\title{
Basal Cell Carcinoma of the Umbilicus: A Comprehensive Literature Review
}

\author{
Saisindhu Narala ${ }^{1}$, Philip R. Cohen ${ }^{1}$ \\ 1. Department of Dermatology, University of California, San Diego \\ $\square$ Corresponding author: Saisindhu Narala, sindhunarala@gmail.com \\ Disclosures can be found in Additional Information at the end of the article
}

\section{Abstract}

Basal cell carcinoma (BCC) typically occurs in sun-exposed sites. Only 16 individuals with umbilical BCC have been described in the literature, and the characteristics of patients with umbilical BCC are summarized. PubMed was used to search the following terms: abdomen, basal cell carcinoma, basal cell nevus syndrome, and umbilicus. Papers with these terms and references cited within these papers were reviewed. BCC of the umbilicus has been reported in five men and 11 women; one man had two tumors. Two patients had basal cell nevus syndrome (BCNS). Other risk factors for BCC were absent. The tumor most commonly demonstrated nodular histology (64\%, 9/14); superficial and fibroepithelioma of Pinkus variants were noted in three and two patients, respectively. The tumor was pigmented in eight individuals. Treatment was conventional surgical excision (87\%, 13/15) or Mohs micrographic surgery (13\%, 2/15); either adjuvant laser ablation or radiotherapy was performed in two patients. The prognosis after treatment was excellent with no recurrence or metastasis $(100 \%, 16 / 16)$. In conclusion, $\mathrm{BCC}$ of the umbilicus is rare. It usually presents as a tumor with a non-aggressive histologic subtype in an individual with no risk factors for this malignancy. There has been no recurrence or metastasis following excision of the cancer.

Categories: Dermatology, Oncology

Keywords: basal cell carcinoma, umbilicus

\section{Introduction And Background}

Basal cell carcinoma (BCC) is the most common type of skin cancer. Although it is rarely fatal, BCC can cause significant morbidity due to local invasion. Ultraviolet exposure is the primary risk factor associated with this malignancy, and therefore, BCCs typically arise on sun-exposed areas [1]. Albeit less commonly, BCCs can arise on sun-sheltered sites such as the axilla, breast, buttock, foot, groin, mouth, nail bed, nipple and areola complex, palm, penis, scrotum, and vulva [2-6]. The characteristics of patients with umbilical BCC, including the woman described in this report, are summarized.

Received 08/07/2016

Review began 08/21/2016

Review ended 08/31/2016

Published 09/07/2016

C) Copyright 2016

Narala et al. This is an open access article distributed under the terms of the Creative Commons Attribution License CC-BY 3.0., which permits unrestricted use, distribution, and reproduction in any medium, provided the original author and source are credited.

\section{Illustrative case}

A 50-year-old Fitzpatrick skin type 5, African-American woman presented for a routine skin examination. She had no prior exposure to arsenic or environmental toxins or ionizing radiation. The patient has basal cell nevus syndrome with multiple previous BCCs; her mother also had pits on the palms and soles and clinodactyly. She had no prior melanoma or squamous cell carcinoma. The umbilical BCC presented as a pigmented plaque measuring $3.0 \times 1.5 \mathrm{~cm}$ on the umbilicus and was located adjacent to a mid-abdominal surgical scar from ventral hernia repair with mesh placement four months prior (Figures $1 A, 1 B$ ). She had a history of several surgeries at the site. 


\section{Cureus}

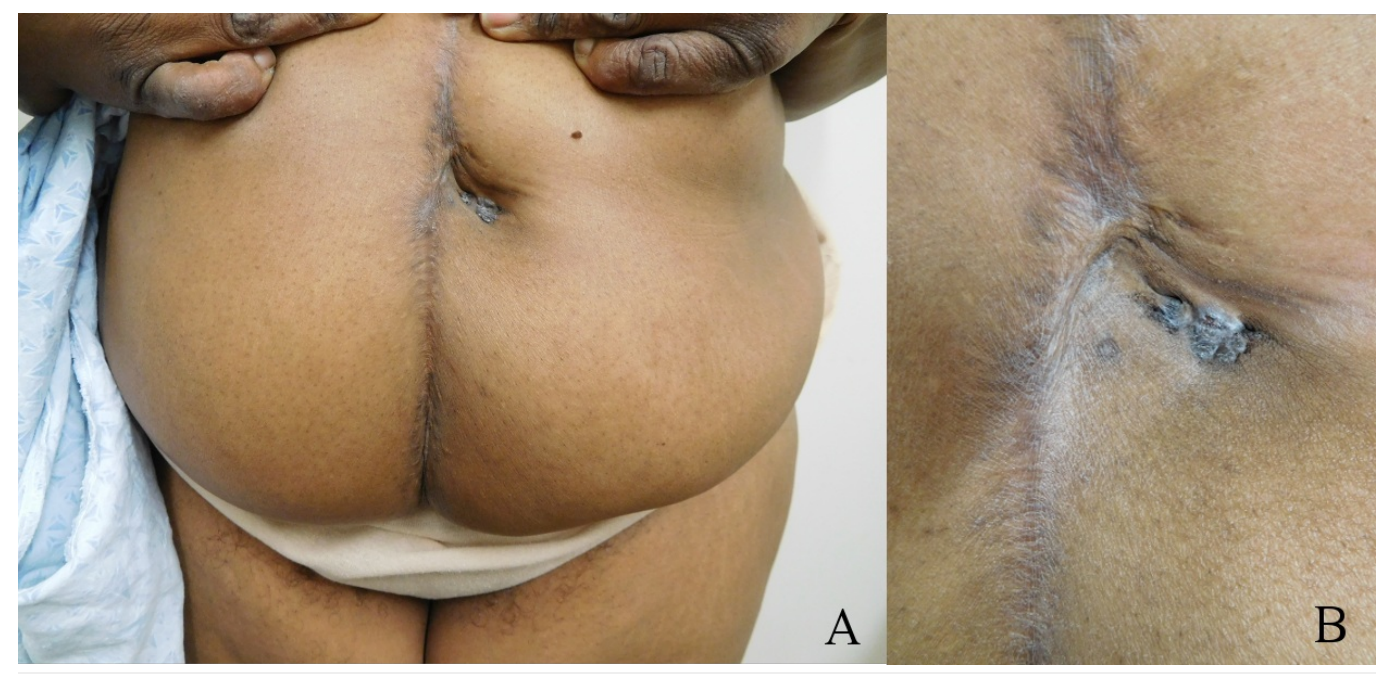

\section{FIGURE 1: Umbilical basal cell carcinoma (BCC) presenting as a pigmented plaque}

Distant (A) and closer (B) views of an umbilical BCC presenting as a pigmented plaque measuring $3.0 \times 1.5 \mathrm{~cm}$ on the umbilicus of a 50-year-old, Fitzpatrick skin type 5, AfricanAmerican woman who presented for routine skin examination.

Punch biopsy of the umbilical plaque revealed nodular aggregates of basaloid tumor cells extending from the epidermis into the dermis (Figure $2 A$ ). In the tumor and surrounding stroma, there were deposits of melanin, some of which were present in melanophages (Figures $2 B, 2 C)$. Mucin, with or without melanin-containing melanophages, was present within the tumor aggregates (Figure 2C). These findings established the diagnosis of a pigmented BCC. Given the proximity of the BCC to the patient's previous ventral hernia surgery incision, she was referred to a surgical oncologist for excision of the residual tumor. 


\section{Cureus}

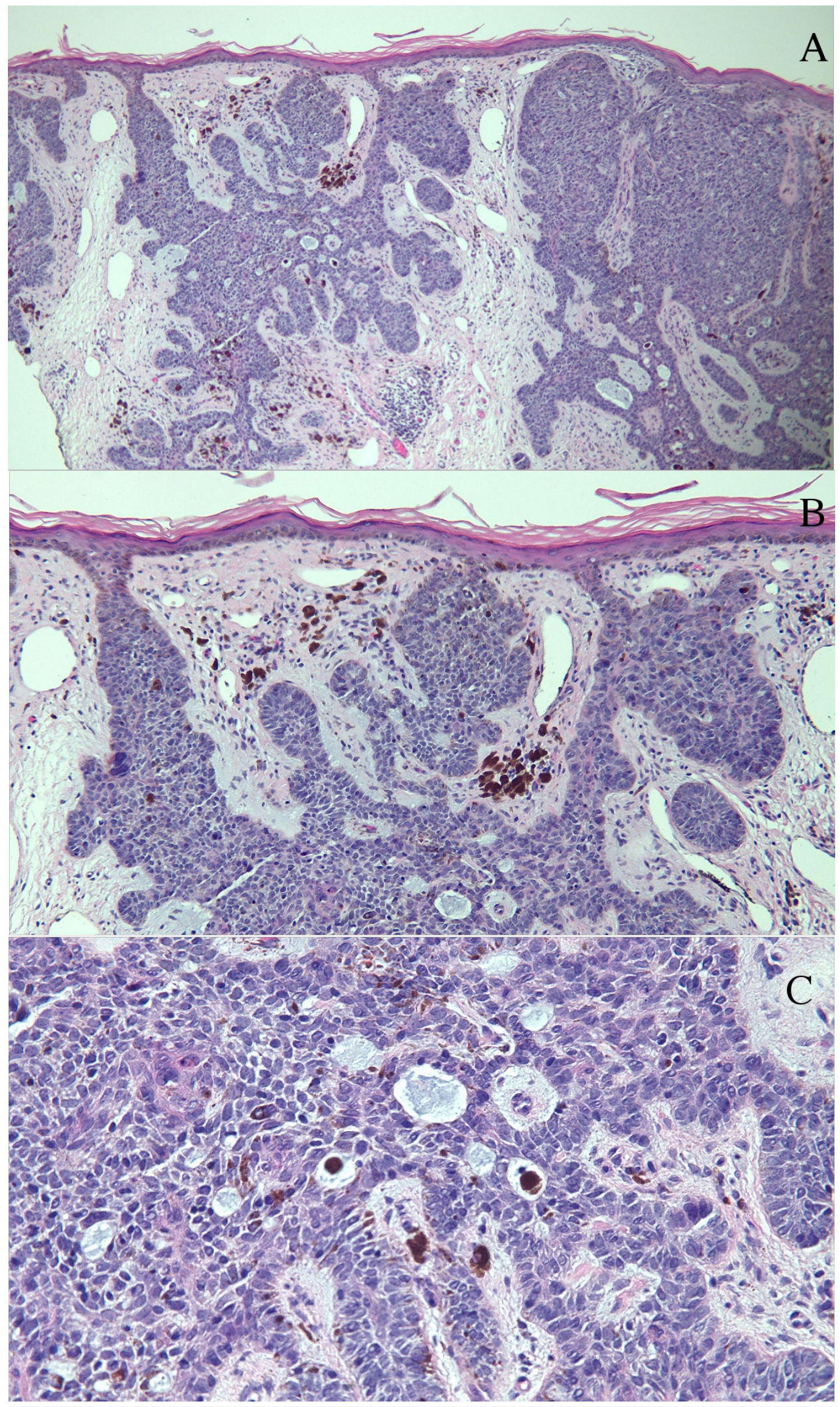

FIGURE 2: Umbilicus punch biopsy histology

Low $(A)$ and higher (B and $C$ ) magnification views of a $3 \mathrm{~mm}$ punch biopsy of the umbilical 
plaque in the woman from Figure 1. Microscopic examination showed nodular aggregates of basaloid tumor cells extending from the epidermis into the dermis (A). In the tumor and surrounding stroma, there were deposits of melanin, some of which were present in melanophages ( $B$ and $C$ ). Mucin, with or without melanin-containing melanophages, is present within the tumor aggregates $(C)$. (hematoxylin and eosin stain: $a=x 4, b=x 10, c=x 40$ ).

\section{Review}

\section{Epidemiology}

Steck and Helwig reported the first cases of umbilical BCC in 1976. They wrote a review of 112 umbilical tumors collected at the Armed Forces Institute of Pathology, two of which were BCCs. Interestingly, one of the tumors was associated with an epidermal inclusion cyst [9].

Subsequently, only a small number of individual reports have been published. We summarized the characteristics of 16 patients with a total of 17 umbilical basal cell carcinomas (Table 1) [7$18]$.

\begin{tabular}{|c|c|c|c|c|c|c|c|c|c|}
\hline Case & $\begin{array}{l}\text { Age, } \\
\text { Race, } \\
\text { Sex }\end{array}$ & $\begin{array}{l}\text { Risk and/or } \\
\text { related factor }\end{array}$ & $\begin{array}{l}\text { Present } \\
\text { before } \mathrm{dx} \\
\text { (mos.) }\end{array}$ & Pigment & $\begin{array}{l}\text { Histologic } \\
\text { type }\end{array}$ & $\begin{array}{l}\text { Size } \\
(\mathrm{cm})\end{array}$ & Treatment & $\begin{array}{l}\text { F/U } \\
\text { (mos., } \\
\text { result) }\end{array}$ & Ref \\
\hline 1 & $21 \mathrm{M}$ & NS & NS & NS & Nodular & NS & Surgery & $48, N R$ & 7 \\
\hline 2 & $48 \mathrm{M}$ & BCNS & NS & NS & Superficial & $6.5 \times 4.5$ & $\begin{array}{l}\text { Surgery, } \\
\text { UP } \mathrm{CO}_{2} \\
\text { LA }\end{array}$ & $15, \mathrm{NR}$ & 8 \\
\hline 3 & $52 \mathrm{M}$ & $\mathrm{CID}^{\mathrm{a}}$ & NS & Path & $\begin{array}{l}\text { Pigmented, } \\
\text { Superficial }\end{array}$ & NS & Surgery & NS & 9 \\
\hline 4 & $54 \mathrm{M}$ & NS & 12 & Clin & Nodular & $4.0 \times 3.0$ & Surgery & $52, \mathrm{NR}$ & 10 \\
\hline $5^{b}$ & $83 \mathrm{M}$ & Hx SCC, BCC & 84 & $\begin{array}{l}\text { Clin, } \\
\text { Path }\end{array}$ & $\begin{array}{l}\text { FeP, } \\
\text { Pigmented, }\end{array}$ & $0.1 \times 0.1$ & NS & NS & 11 \\
\hline 6 & $27 \mathrm{Ca} \mathrm{F}$ & NS & 24 & NS & Nodular & 0.4 & Surgery & NS & 12 \\
\hline 7 & $43 \mathrm{~F}$ & NS & 240 & NS & Superficial & $2.7 \times 1.5$ & MMS & NS & 13 \\
\hline 8 & 50 AA F & BCNS, PS ${ }^{\mathrm{C}}$ & 36 & $\begin{array}{l}\text { Clin, } \\
\text { Path }\end{array}$ & $\begin{array}{l}\text { Nodular, } \\
\text { Pigmented, }\end{array}$ & $3.0 \times 1.5$ & Surgery & TP & CR \\
\hline 9 & $54 \mathrm{~F}$ & $P S^{d}$ & 24 & NS & Nodular & 2.5 & Surgery & $12, N R$ & 14 \\
\hline 10 & $67 \mathrm{~F}$ & NS & 3 & Clin & $\mathrm{FeP}$ & NS & Surgery & NS & 15 \\
\hline 11 & $68 \mathrm{~F}$ & NS & 6 & Clin & Nodular & $1.8 \times 1.5$ & Surgery & $24, \mathrm{NR}$ & 10 \\
\hline 12 & $71 \mathrm{~F}$ & NS & NS & NS & NS & NS & Surgery & NS & 16 \\
\hline 13 & $75 \mathrm{~F}$ & NS & 12 & NS & NS & NS & Surgery & NS & 17 \\
\hline \multirow[t]{2}{*}{14} & $76 \mathrm{~F}$ & NS & NS & NS & NS & NS & Surgery & NS & 9 \\
\hline & & & & & & & MMS, & & \\
\hline
\end{tabular}




\section{Cureus}

$\begin{array}{llllllllll}15 & 80 \mathrm{CaF} & \text { NS } & 24 & \text { Clin } & \text { Nodular } & 2.0 \times 1.8 & \text { radiation } & \text { NS } & 18 \\ 16 & 94 \mathrm{~F} & \text { NS } & 12 & \text { Clin } & \text { Nodular } & 2.0 \times 2.0 & \text { Surgery } & 12, \text { NR } & 10\end{array}$

\section{TABLE 1: Characteristics of Patients with Umbilical Basal Cell Carcinoma}

Abbreviations: $\mathrm{AA}=$ African-American; $\mathrm{BCC}=$ basal cell carcinoma; $\mathrm{BCNS}=$ basal cell nevus syndrome; $\mathrm{Bx}=$ biopsy; Ca =

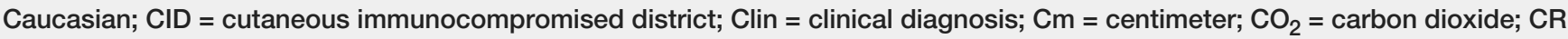
= current report; Dx = diagnosis; FeP = fibroepithelioma of Pinkus; F/U = follow-up; Hx = history; LA = laser ablation; MMS = Mohs micrographic surgery; Mos = months; Path = pathologic diagnosis; PS = prior scar; NR = no recurrence; NS = not stated; Ref = reference; SCC = squamous cell carcinoma; TP - treatment pending; UP = ultrapulse

aThe patient had an epidermal inclusion cyst at the site of the tumor.

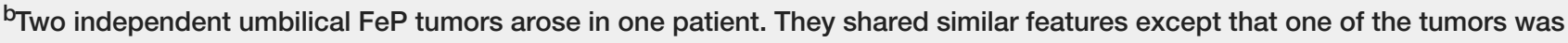
pigmented.

${ }^{\mathrm{C}}$ The patient had a ventral hernia repair at the site.

dThe patient had a scar from a prior laparoscopic port at the site.

Umbilical BCCs were described in five men (31\%) and 11 women (69\%) (men: women = 1: 2.2). The patients ranged in age from 21 to 94 years, with a median age of 61 years at the time of diagnosis. The men ranged from 21 to 83 years of age (median $=52$ years), and the women ranged from 27 to 94 years of age (median $=67.5$ years). The majority of men were diagnosed before their sixth decade $(80 \%, 4 / 5)$ while the majority of women were diagnosed during or after their sixth decade $(60 \%, 6 / 10)$. The race was not specified for most of the patients with umbilical tumors. Two patients were Caucasian and one patient was African-American. Two patients with no reported race were described as having fair skin (Cases 1 and 7).

\section{Clinical presentation}

Many of the tumors were diagnosed after a change in their morphology or the onset of symptoms. Three patients reported rapidly increasing size (Cases 4,10 , and 11). Two patients noted erosion or ulceration (Cases 10 and 13) and two patients noted spontaneously bleeding after incidental contact (Cases 7 and 9). The tumor was asymptomatic and only recognized during routine screening in four patients (Cases 1, 2, 5, and 8).

\section{Tumor duration before diagnosis}

The presence of the umbilical tumor prior to diagnosis was described in only 11 patients and ranged from 240 months (Case 5) to three months (Case 10), with a median of 24 months. The tumor had been present less than or equal to two years in $73 \%$ of patients $(8 / 11)$ and had been present for six months or less in $27 \%$ of patients (3/11). Interestingly, one patient described a history of a slow-growing, red, scaly plaque around the umbilicus that was present for 20 years. It was originally diagnosed as eczematous dermatitis and treated with topical steroids and antibiotics with no resolution. After the lesion began bleeding spontaneously, BCC was diagnosed (Case 7).

\section{Location}


BCCs typically arise on sun-exposed areas, such as the head and neck [19]. BCCs arising in the truncal region are not uncommon [4]. However, primary tumors of the umbilicus are very rare, and only 16 patients have been reported in the literature (Table 1). Metastatic tumors to the umbilicus (Sister Mary Joseph nodules) are much more common than primary tumors and are usually gastrointestinal adenocarcinomas [20].

\section{Morphology}

Many of the umbilical BCCs presented as nodules (Cases 4, 6, 9, 10, 11, and 16); however, some were described as small papules (Cases 1 and 13) or plaques (Cases 2, 7, and 8). Some were described as asymmetric in appearance (Cases 2 and 10). The tumors were as small as $4 \mathrm{~mm}$ (Case 6) to as large as $2.7 \times 1.5 \mathrm{~cm}$ (Case 7). One tumor demonstrated erosion (Case 10), one tumor demonstrated ulceration (Case 13), and two tumors demonstrated bleeding on contact (Cases 7 and 9).

The color of the tumor was described in 12 patients. It was flesh-colored in four patients (Cases $1,6,9$, and 13) and red in one patient (Case 7). A pigmented BCC was clinically observed in seven patients (Cases 4, 6, 8, 10, 11, 15, and 16). This represented $88 \%$ ( $7 / 8$ patients) of those with a diagnosis of pigmented BCC; the color of the lesion was not described in one patient whose pathology demonstrated pigmented BCC (Case 3).

\section{Pathology}

The histologic subtype of umbilical BCC was described for 14 of the 17 tumors. All of the tumors had a histologic subtype that demonstrates less aggressive behavior [21]. Nodular histology was observed in 64\% (9/14 carcinomas), including a patient whose tumor had mixed histology (Case 2). Three of the patients had a superficial BCC (Cases 2, 3, and 7).

Previous studies have shown that BCCs in sun-sheltered regions predominantly are the superficial variant, while those in sun-exposed regions demonstrate a nodular histology [22]. In contrast, the majority of patients with umbilical BCC demonstrated nodular histology (Table 1).

A fibroepithelioma of Pinkus variant of BCC was also observed in two patients. A 67-year-old woman presented with a progressively enlarging dark brown to blue nodule over the umbilicus for three months. The patient had no conventional risk factors for BCC (Case 10). An 83-yearold man presented with two adjacent pink, polyploid masses arising from the umbilicus. The biopsy revealed two independent fibroepitheliomas of Pinkus tumors (Case 5). Fibroepithelioma of Pinkus subtype of BCC has a predilection for the trunk, in contrast to classic BCC, which arises in sun-exposed areas [23]. However, fibroepithelioma of Pinkus has also been described in other non-sun exposed sites, such as the axilla [5, 24-26].

Pigmented BCC, microscopically characterized by melanin in the tumor cells, the surrounding stroma, or both, was described in two of the patients with clinically pigmented lesions (Cases 5 and 8) and the one patient whose tumor color was not reported (Case 3).

\section{Risk factors}

In addition to ultraviolet radiation exposure, risk factors for BCC include other environmental exposures, such as ionizing radiation, arsenic, asbestos, and dry cleaning solvents [27]. Other associations that may increase risk to develop BCC include trauma or chronic inflammation at the site, immunosuppression, genodermatoses (basal cell nevus syndrome (BCNS), Bazex syndrome, epidermolysis bullosa simplex, oculocutaneous albinism, Rombo syndrome, and xeroderma pigmentosum), history of prior BCC, and certain physical phenotypic characteristics (light color of eyes, hair, and skin) [5, 28-30]. None of the patients with umbilical BCCs had a 
history of extensive sun exposure to that region of their body. However, 31\% (5/16) of patients with umbilical BCC had either an established or possibly associated tumor-related risk factor (Table 1).

A history of trauma and scarring may have contributed to the development of umbilical BCC in two patients. A 54-year-old woman underwent paraumbilical port placement for laparoscopic surgery, which resulted in an umbilical scar. BCC arising from the umbilical scar was diagnosed 21 years after the initial trauma (Case 9). The second patient, a 50-year-old African-American woman with BCNS, had several surgeries, including a ventral hernia repair four months earlier, at the site (Case 8). The mechanism of BCC arising from trauma remains elusive [14]. There have been at least nine reported cases of BCC arising from elective surgical scars, none of which involved the umbilicus [14].

Another patient had an epidermal inclusion cyst at the location of the tumor. Epidermal inclusion cyst is a benign epithelial lesion. Although it is not considered a risk factor for BCC, a few reports have described patients in whom a squamous cell carcinoma arose from an epidermal cyst [31-33]. Hence, the epidermal inclusion cyst may have represented a cutaneous immunocompromised district enabling the development of a BCC of the site [34].

Two patients had BCNS. BCNS is an autosomal dominant disorder that is associated with the development of multiple BCCs. In these individuals, BCCs usually develop in adolescence, with a median age of onset of 20 years [35]. The patients with BCNS and umbilical BCC developed their tumors at a younger age than the median age for all of the patients with BCCs at this location (49 versus 61 years). Similar to these individuals with BCNS and umbilical BCCs, BCCs have also been discovered in other sun-sheltered sites in patients with BCNS; these include the axilla, inguinal area, and buttocks [36-38].

\section{Pathophysiology}

The majority of patients with umbilical BCC had no associated risk factors. Investigators have previously attempted to explain the pathogenesis of BCC arising in areas with no significant sun exposure. Strickland and colleagues postulated that ultraviolet radiation at distant sunexposed sites may lead to a suppression of immune surveillance that in turn allows BCCs to develop in sun-protected sites [39]. Many have endorsed this theory as contributing to the formation of BCCs in other covered sites, such as the genital regions [40] and the axilla [25-26, 41]. Other researchers have suggested that local alterations in cell matrix interactions lead to changes in skin texture, shape, and tension that may contribute to tumor formation in sunprotected areas [42].

\section{Treatment}

All of the patients with umbilical BCC had or shall have a surgical excision of the tumor. Mohs micrographic surgery (MMS) was performed for two patients (Cases 5 and 7). MMS is generally reserved for tumors located in areas of cosmetic concern or embryonal growth plates or both. However, MMS was justified in one patient because the tumor had invaded the umbilical stalk and there was a risk for seeding the peritoneum; the woman also received adjuvant radiation therapy because of the difficulty in monitoring recurrence in this anatomic area (Case 15). Similarly, MMS was performed in the second patient because the tumor was noted to extend deep into the umbilicus (Case 7). One patient with BCNS received carbon dioxide laser ablation in addition to surgery. The clinicians had successful experience with this combination treatment for plaques involving both concave and convex areas of the skin, such as those in the umbilicus, and purport that it may help reduce the surgical burden in BCNS (Case 2). 


\section{Prognosis}

The prognosis for patients with umbilical BCC appears to be good after treatment. Follow-up was described for six patients and ranged from 12 months to 52 months. No recurrence or metastasis was reported for any of the patients (Table 1).

\section{Conclusions}

BCC appearing in the umbilicus is rare. Only 17 tumors in 16 patients have been described in the literature appearing at a median age of 61 years. Umbilical BCCs are 2.2 times more common in women than in men. In $80 \%$ of the patients, the tumor had been present for two or fewer years. The carcinoma typically presented as a nodule, papule, or plaque and the most common symptoms were ulceration and bleeding. The tumor was pigmented clinically or pathologically or both in eight patients. The most frequent histologic subtype was nodular; some of the patients had tumors that were fibroepithelioma of Pinkus, superficial, or mixed (nodular and superficial) histologic variant. Risk and/or possibly related factors that may be associated with BCC were observed in only $31 \%$ of patients (5/16); these included basal cell nevus syndrome, epidermal inclusion cyst, history of non-melanoma skin cancer, and previous surgical scar. The majority of patients with umbilical BCC had no tumor-related risk factors and did not have a history of prolonged sun exposure to the area. It has been postulated that decreased immune surveillance from ultraviolet exposure at other sites or local alterations in cell-matrix interactions or both may contribute to BCC in sites with little sun exposure, such as the umbilicus. Surgical management of the carcinomas was effective; the tumors were successfully treated by excision with or without examination of the margins during surgery. The prognosis of umbilical BCC is excellent; there have been neither recurrence nor metastasis following surgical excision of the neoplasm.

\section{Additional Information \\ Disclosures}

Conflicts of interest: In compliance with the ICMJE uniform disclosure form, all authors declare the following: Payment/services info: All authors have declared that no financial support was received from any organization for the submitted work. Financial relationships: All authors have declared that they have no financial relationships at present or within the previous three years with any organizations that might have an interest in the submitted work. Other relationships: All authors have declared that there are no other relationships or activities that could appear to have influenced the submitted work.

\section{References}

1. Marzuka AG, Book SE: Basal cell carcinoma: pathogenesis, epidemiology, clinical features, diagnosis, histopathology, and management. Yale J Biol Med. 2015, 88:167-79.

2. Rahbari H, Mehregan AH: Basal cell epitheliomas in usual and unusual sites . J Cutan Pathol. 1979, 6:425-31. 10.1111/j.1600-0560.1979.tb01165.x

3. Robins P, Rabinovitz HS, Rigel D: Basal-cell carcinomas on covered or unusual sites of the body. J Dermatol Surg Oncol. 1981, 7:803-6. 10.1111/j.1524-4725.1981.tb00170.x

4. Betti R, Bruscagin C, Inselvini E, Crosti C: Basal cell carcinomas of covered and unusual sites of the body. Int J Dermatol. 1997, 36:503-5. 10.1046/j.1365-4362.1997.00139.x

5. Cohen PR: Basal cell carcinoma of the axilla: review of the world literature . Am J Clin Dermatol. 2014, 15:95-100. 10.1007/s40257-014-0066-8

6. Chun KA, Cohen PR: Basal cell carcinoma of the nipple-areola complex: a comprehensive review of the world literature. Dermatol Ther (Heidelb). 2016, 6:379-95. 10.1007/s13555-0160128-3

7. Ramirez P, Sendagorta E, Feito M, Gonzalez-Beato M, Mayor M, Pizarro A: Letter: Umbilical basal cell carcinoma in a 21-year-old man: Report of an exceptional case and dermatoscopic 
evaluation. Dermatol Online J. 2011, 17:16.

8. Krunic AL, Viehman GE, Madani S, Clark RE: Microscopically controlled surgical excision combined with ultrapulse $\mathrm{CO} 2$ vaporization in the management of a patient with the nevoid basal cell carcinoma syndrome. J Dermatol. 1998, 25:10-12. 10.1111/j.1346-

8138.1998.tb02337.x

9. Steck WD, Helwig EB: Tumors of the umbilicus . Cancer. 1965, 18:907-15. 10.1002/10970142(196507)18:7<907::AID-CNCR2820180721>3.0.CO;2-U

10. Nakamura Y, Teramoto Y, Tanaka R, Nakamura Y, Maruyama H, Fujisawa Y, Sato S, Fujimoto M, Yamamoto A: Surgical management of umbilical basal cell carcinoma: Published work review and the optimal depth of surgical excision. J Dermatol. 2014, 41:992-95. 10.1111/13468138.12640

11. Inskip M, Longo C, Haddad A: Two adjacent individual fibroepithelioma of Pinkus of the umbilicus-one pink, one pigmented-a case report and review of the literature. Dermatol Pract Concept. 2016, 6:17-20.

12. Walker SL, Banerjee P, Marsden RA: Basal cell carcinoma arising at the umbilicus . Clin Exp Dermatol. 2001, 26:458-59. 10.1046/j.1365-2230.2001.00857-4.x

13. Etter L, Cook JL: Basal cell carcinoma of the umbilicus: a case report and literature review . Cutis. 2003, 71:123-26.

14. Durrani AJ, Miller RJ, Davies M: Basal cell carcinoma arising in a laparoscopic port site scar at the umbilicus. Plast Reconstr Surg. 2005, 116:348-50. 10.1097/01.PRS.0000173546.88835.CB

15. Lin TC, Lee TL, Lin TY, Wu PY: An infrequent case of neoplasm with fibroepithelioma of pinkus and hidradenomatous features arising at the umbilicus: a rare finding. Am J Dermatopathol. 2011, 33:750-52. 10.1097/DAD.0b013e31820978cf

16. Schneider HJ, Young AE: Sister Joseph’s nodule. Eur J Surg Oncol. 1998, 24:155. 10.1016/S0748-7983(98)91797-8

17. Ramos-e-Silva S, Marques J, Ramos-e-Silva M, Canedo T, Cuzzi T: Umbilical basal cell carcinoma: an unusual location. J Am Acad Dermatol. 2013, 68:AB167. 10.1016/j.jaad.2012.12.692

18. Chuang GS, Lu LK, Finn D: Basal cell carcinoma invading the umbilical stalk excised with Mohs micrographic surgery: case report and review of umbilical anatomy. Dermatol Surg. 2009, 35:1290-93. 10.1111/j.1524-4725.2009.01228.x

19. Pearl DK, Scott EL: The anatomical distribution of skin cancers . Int J Epidemiol. 1986, 15:5026. 10.1093/ije/15.4.502

20. Zhou Z, Zhang D: Sister Mary Joseph nodule. Clin Case Rep. 2015, 4:214-15. 10.1002/ccr3.460

21. Cohen PR, Schulze KE, Nelson BR: Basal cell carcinoma with mixed histology: a possible pathogenesis for recurrent skin cancer. Dermatol Surg. 2006, 32:542-51. 10.1111/j.15244725.2006.32110.x

22. Bastiaens MT, Hoefnagel JJ, Bruijn JA, Westendorp RG, Vermeer BJ, Bouwes Bavinck JN: Differences in age, site distribution, and sex between nodular and superficial basal cell carcinoma indicate different types of tumors. J Invest Dermatol. 1998, 110:880-84. 10.1046/j.1523-1747.1998.00217.x

23. Haddock ES, Cohen PR: Fibroepithelioma of Pinkus revisited. Dermatol Ther (Heidelb). 2016, 6:347-62. 10.1007/s13555-016-0123-8

24. Cohen PR, Tschen JA: Fibroepithelioma of Pinkus presenting as a sessile thigh nodule . Skinmed. 2003, 2:385-87. 10.1111/j.1540-9740.2003.02491.x

25. Betti R, Crosti C, Moneghini L, Crespi E, Menni S: Axillary basal cell carcinoma: additional 25 patients and considerations. J Eur Acad Dermatol Venereol. 2011, 25:858-60. 10.1111/j.14683083.2010.03853.x

26. Hayes AG, Berry AD 3rd: Basal cell carcinoma arising in a fibroepithelial polyp . J Am Acad Dermatol. 1993, 28:493-95. 10.1016/S0190-9622(08)81763-X

27. Gallagher RP, Bajdik CD, Fincham S, Hill GB, Keefe AR, Coldman A, McLean DI: Chemical exposures, medical history, and risk of squamous and basal cell carcinoma of the skin. Cancer Epidemiol Biomarkers Prev. 1996, 5:419-24.

28. Chinem VP, Miot HA: Epidemiology of basal cell carcinoma (Article in English, Portuguese) . An Bras Dermatol. 2011, 86:292-305. 10.1590/S0365-05962011000200013

29. Rubin AI, Chen EH, Ratner D: Basal cell carcinoma. N Eng J Med. 2005, 353:2262-69. 10.1056/NEJMra044151

30. Wong CS, Strange RC, Lear JT: Basal cell carcinoma. BMJ. 2003, 327:794-98. 
10.1136/bmj.327.7418.794

31. Jehle KS, Shakir AJ, Sayegh ME: Squamous cell carcinoma arising in an epidermoid cyst . Br J Hosp Med (Lond). 2007, 68:446. 10.12968/hmed.2007.68.8.24499

32. Chiu MY, Ho ST: Squamous cell carcinoma arising from an epidermal cyst. Hong Kong Med J. 2007, 13:482-84.

33. Ziadi S, Trimeche M, Hammedi F, Sriha B, Jomaa W, Mokni M, Korbi S: Squamous cell carcinoma arising from an epidermal inclusion cyst: A case report. N Am J Med Sci. 2010, 2:46-47.

34. Ruocco V, Ruocco E, Piccolo V, Brunetti G, Guerrera LP, Wolf R: The immunocompromised district in dermatology: A unifying pathogenic view of the regional immune dysregulation. Clin Dermatol. 2014, 32:569-76. 10.1016/j.clindermatol.2014.04.004

35. John AM, Schwartz RA: Basal cell naevus syndrome: an update on genetics and treatment . Br J Dermatol. 2016, 174:68-76. 10.1111/bjd.14206

36. Samela PC, Tosi V, Cervini AB, Bocian M, Buján MM, Pierini AM: Nevoid basal cell carcinoma syndrome: our experience in a pediatric hospital (Article in English, Spanish). Actas Dermosifiliogr. 2013, 104:426-33. 10.1016/j.adengl.2013.04.006

37. LeSueur BW, DiCaudo DJ, Connolly SM: Axillary basal cell carcinoma. Dermatol Surg. 2003, 29:1105-108. 10.1046/j.1524-4725.2003.29346.x

38. Cohen PR: Axillary basal cell carcinoma in patients with Goltz-Gorlin syndrome: report of basal cell carcinoma in both axilla of a woman with basal cell nevus syndrome and literature review. Dermatol Online J. 2014, 20:pii: 13030/qt7pg665b9.

39. Strickland PT, Creasia D, Kripke ML: Enhancement of two-stage skin carcinogenesis by exposure of distant skin to UV radiation. J Natl Cancer Inst. 1985, 74:1129-34.

40. Gibson GE, Ahmed I: Perianal and genital basal cell carcinoma: A clinicopathologic review of 51 cases. J Am Acad Dermatol. 2001, 45:68-71. 10.1067/mjd.2001.114588

41. Lin CT, Chen SG, Chen TM, Chang SC: Axillary basal cell carcinoma: case report and literature review. Acta Dermatovenerol Croat. 2011, 19:107-109.

42. Heckmann M, Zogelmeier F, Konz B: Frequency of facial basal cell carcinoma does not correlate with site-specific UV exposure. Arch Dermatol. 2002, 138:1494-97.

10.1001/archderm.138.11.1494 